\title{
Consumers' preferences for preparing stoles using blue pottery motifs
}

\author{
ALEEZA SHARMA AND VANDANA GANDOTRA
}

Received: 21.10.2016; Revised: 17.11.2016; Accepted: 25.11.2016

Author for Correspondence :

\section{ALEEZA SHARMA}

Department of Apparel and Textile Science, College of Home Science,

Punjab Agricultural University,

LUDHIANA (PUNJAB) INDIA

Email : aleeza.sharma@yahoo.com
ABSTRACT : The present study was undertaken for design development of silk stoles using blue pottery motifs. The preferences for the selection of blue pottery motifs were taken from the panel of ten judges from Department of Apparel and Textile Science. Eighteen sheets of designs were prepared using blue pottery motifs in order of the preferences. Out of which the most preferred six designs of stoles were used to prepare the stoles. The preferences of sixty college going girls were taken from Department of Apparel and Textile Science, College of Home Science, PAU, Ludhiana. On the basis of preferences of respondents, six stoles were developed using blue pottery motifs with screen printing technique.

KEY WORDS: Motifs, Stole, Embellishments, Factors

- HOW TO CITE THIS PAPER : Sharma, Aleeza and Gandotra, Vandana (2016). Consumers' preferences for preparing stoles using blue pottery motifs. Asian J. Home Sci., 11 (2) : 441-445, DOI: 10.15740/HAS/ AJHS/11.2/441-445. 